\title{
Conceptual Metaphor on Discoursal Organization A Case Study of The Book of Tao and Teh
}

\author{
Xiaojing Yin \\ Shandong University of Finance and Economics, Shandong, China \\ Email: lindayin@sogou.com
}

\begin{abstract}
Metaphor in the cognitive linguistic view means a way of understanding relatively abstract concepts in terms of concrete ones. Conceptual metaphor plays an important role in human conceptualization. It guides perceptions, structuralize experience and create new insight. We takes The Book of Tao and Teh as an example to illustrate how conceptual metaphors function at discoursal level because Lao Tzu's brilliant ideas, so impressive and wonderful, are often said to mark the peak of classical Chinese philosophy. Conceptual metaphor can account for the cohesion of the discourse and metaphorical expressions, especially lexis, are cohesive tokens to achieve explicit coherence in texts. And we confirm the hypothesis that conceptual metaphor in discourse can help to guarantee textual cohesion and coherence. The systematicity and coherence of metaphor is of great importance to discourse construction.
\end{abstract}

Index Terms - conceptual metaphor, Tao and The, cohesion and coherence

\section{INTRODUCTION}

Metaphor, in a broad sense, is pervasive and essential in language and thought. Within the cognitive framework, conceptual metaphor studies have been successfully done concerning its nature, types, and characteristics. However, studies on textual functions of conceptual metaphor, such as its cohesive and coherent textual functions, are rare. Conceptual metaphor theories provide us with a foothold from which people can observe the internal structure of a discourse. In fact, the adoption of conceptual metaphor in discourse contributes to cohesion and coherence in a discourse and make it more vivid and much easier to understand. The purpose of this thesis is to apply insights from the contemporary theory of conceptual metaphor to the analysis of cohesive and coherent functions of conceptual metaphor in discourse studies.

Lao Tzu is often said to mark the peak of classical Chinese philosophy. Lao Tzu says all things of the world are born from Being and being from nothingness. Tao embodies both Being and Nothingness, and functions as a law underlying the Way, dao in Chinese, which is the universal rule that governs this world. Though Tao exists everywhere, it is vague and intangible, which cannot be easily seen or heard or touched by ordinary people. Since Tao is intangible, unseen, how can people follow it? The sage, master of Taoism, Lao Tzu, resorts to the WATER metaphor. He defines TAO as WATER. This book covers subjects comprehensively ranging from philosophy, history, politics, ethics, and to the cultivation of man's mind. Centering around Tao, the core of Lao Tzu philosophy, Taoism is systematically constructed with four integral parts: Tao as the ontological being; Tao as the dialectic law; Tao as a practical guide to worldly affairs; and Tao keeps on the move in terms of its uniqueness.

According to cognitive linguistics, the working mechanism for the cross-domain mapping is relied on the human being's bodily experience. The embodiment of TAO is drawn from the soft, flexible, pure, powerful and static properties of water. There is a coherent system of these metaphorical concepts, TAO IS WATER; TAO IS MOTHER; TAO IS FEMALE; etc. and a corresponding coherent system of metaphorical expressions. Cohesiveness and coherence of the discourse are achieved based on those metaphors. They function in two ways: First, one conceptual metaphor, the WATER metaphor establishes the heuristic frame for the rest of the discourse sequence. Second, the WATER metaphor creates many other metaphors and metaphorical expressions. Thus, all metaphors in the discourse work in a systematic way.

In conceptual metaphor theory, "A is B" is the formula of conceptual metaphor which can be realized by a set of metaphorical expressions, and a group of subordinate conceptual metaphors, for instance, TAO IS MOTHER; TAO IS FEMALE, etc. are drawn from TAO IS WATER. They share the same target domain, TAO and TEH, and four different source domains, female, valley, children and root, are used to highlight different aspects of the target domain. They form a hierarchical system, and the four conceptual metaphors are coherent based on this system. The system gives rise to a set of metaphorical expressions in the text. So the sample text is coherent based on the coherent relationship between the central conceptual metaphor and its sub-metaphors.

(1) All the streamlets flow towards the river and the sea, because the latter takes the lower position. (Chapter 66)

(2) Hence one should gain an insight into the subtlety of Tao by observing Nothingness, and should gain an insight into the beginning of Tao by observing Existence or Being. These two things, Nothingness and Existence, are of the same origin but different in name. (Chapter 1) 
Judging from (1) and (2), we can say that the similarity between WATER and TAO is the key to understanding Lao Tzu's inscrutable TAO and TEH.

\section{Discourse Organization of The BoOK OF TAO AND TeH}

All the conceptual metaphors in The Book of Tao and Teh have roles to play in the monitoring of the discourse production. The contribution of metaphor to textual coherence is fundamentally attributable to its systematicity and coherence. van Dijk (1985) introduced the notion of macrostructure in order to provide an abstract semantic description of the global content of a text. In more comprehensible terms, it refers to the main idea or the topic of the text. In The book Tao and Teh, four integral parts are centered on: Tao as ontological being, forms the essential of Lao Tzu's outlook upon the world; Tao as a practical guide to worldly affairs, means its specific application to explain society, history, life and so on; Tao as the epistemological tool, explains how mankind can approach the Taoist being; Tao as the dialectic law embodies Lao Tzu's methodology.

According to Lakoff and Johnson (1980, p7), the language we use to talk about that aspect of the concept is systematic because the metaphorical concept is systematic. For example, TAO IS WATER and TEH IS WATER, we understand and conceptualize arguments in terms of water in a systsystem represented by a systematic way. The WATER metaphor, like a global proposition and a heuristic frame, governs and controls the generation of other metaphors as well as a set of metaphorical expressions. It leads the information flow of the text by structural mapping.

According to Lakoff and Johnson (1980), since two purposes cannot be served at once by a single metaphor, two or more metaphors are often needed. There will be no one single metaphor that allows us to get a handle simultaneously on both the direction of the argument and the content of the argument and thus we have separate metaphors TAO IS WATER and TAO IS MOTHER. They are coherent in the sense that the different source domains are unified for this single concept. The WATER metaphor creates many other metaphors for instance, TAO IS MOTHER; TAO IS FEMALE, etc. and they are coherent as a whole. The coherence of metaphor includes the coherence within a single metaphor, TAO IS WATER; coherence between different aspects of this single concept and coherence across different conceptual metaphors, for instance, TAO IS WATER NOURISHING LIFE; TAO IS WATER FLOWING DOWNWARDS, etc.

Systematicity, in this thesis, is studied at two levels: the conceptual level and the linguistic level. Goatly(1997) stated that "Metaphor can be used, consciously or subliminally, to structure the development of a text, as the organizing principle which gives the text a lexical cohesion.(p.163)

As discourse develops, metaphorical expressions derived from the conceptual metaphor create lexical cohesive chains in discourse. The WATER metaphor is systematic and it creates numerous linguistic expressions. The most prominent cohesive evidence the conceptual metaphor represents in this book is lexis which, in most cases, contributes to a certain semantic category, which are illustrated in the following:

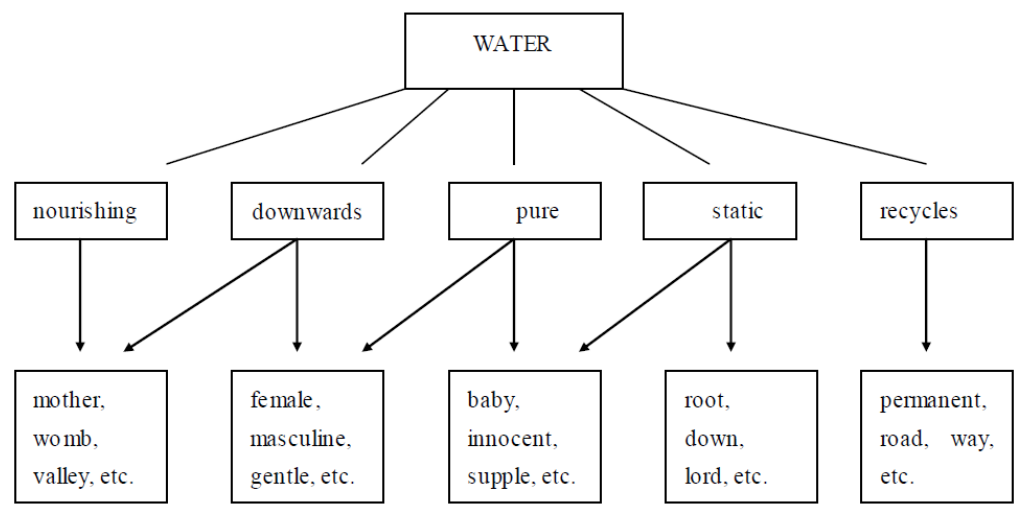

Figure 1. Cohesive Chains in The Book of Tao and The

(3) The perfect goodness is like water; water approaches all things instead of contending with them. (Chapter 8)

(4) Man takes Earth as his model, Earth takes Heaven as its model; Heaven takes Tao as its model; Tao takes what is natural as its model.(Chapter 25)

(5) The perfect goodness is like water. Hence it comes close to Tao. (Chapter8)

(6) The word, Nothingness, may be used to designate the beginning of Heaven and Earth; the word Existence or Being may be used to designate the mother of all things. (Chapter1)

(7) Though knowing what is masculine; you are ready to play the role of female and content to be a stream in the world. (Chapter 28)

(8)I do not know whose son he is, it seems to have appeared before the existence of God. (Chapter 4)

We can find these lexis appear in clusters and chains. The WATER metaphor links the passage as a thread through some cohesive devices. The cohesive chains are linked by repeating the source domain terms, by using the same word or similar or approximate words or utilizing a superordinate word as well as a general word, such as, water in (3); model, 
Tao in (4), mother, masculine female, son, in (6), (7), (8) to name just a few. As a result, there is a systematic lexical cohesive network in the process of metaphor extension. Thus, the metaphorical expressions form a coherent system. Sometimes two conceptual metaphors are used to highlight different aspects of the same target domain, with each entails a set of metaphorical expressions, and these groups have some overlappings. The conceptual metaphor TAO IS WATER generates a metaphorical expression (5) and TEH IS MOTHER gives rises to (6). Water and mother have another overlapping that they both tend to take the lower position so (7) is apprehensible.

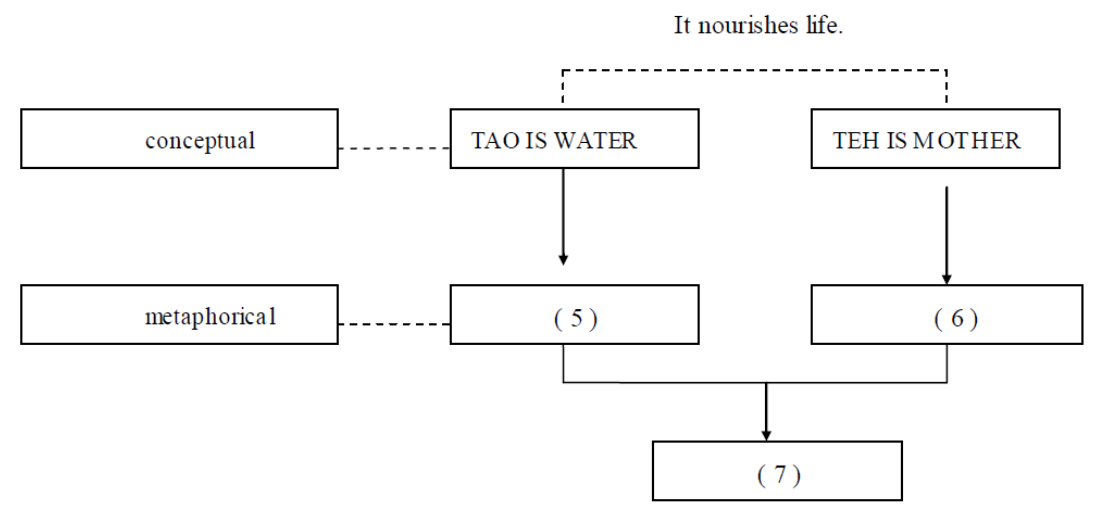

Figure 2. Overlappings in Metaphorical Expressions.

More importantly, the discourse is structured in a way that the concepts and ideas in both the target domain and the source domain revolve around the central WATER metaphor. While the metaphorical expressions create cohesion on the surface text, the underlying systematic metaphorical concepts which govern the metaphorical expressions make contribution to coherence at a deep level.

(9) All the streamlets flow towards the river and the sea, because the latter takes the lower position, hence the latter becomes the king of countless valleys. (Chapter 60)

Lakoff and Johnson (1980) states that there are two sources of complexity: there are often many metaphors that partially structure a single concept and when we discuss one concept, we use other concepts that are themselves understood in metaphorical terms, which leads to further overlapping of metaphors. For example, in this book, the WATER, MOTHER, VALLEY metaphor are used to talk about Tao. And the WATER metaphor is applied to talk about the Valley metaphor as in (9).

Metaphorical extension helps form a systematic relationship between metaphorical concepts and make a discourse develop in a coherent way. It has been found that there also exists a set of parallel classifications in different source domains, for instance, TAO IS WATER and TAO IS MOTHER, etc.

Metaphorical entailments can characterize a coherent system of metaphorical concepts and a corresponding coherent system of metaphorical expressions for those concepts (Lakoff \& Johnson, 1980, p.9). In this case, different source concepts, water, mother, female, baby, etc. are used to talk about the same target domain, Tao and Teh, and different conceptual metaphors, TAO IS MOTHER; TAO IS WATER; TEH IS WATER; TEH IS BABY; TEH IS FEMALE, etc. are also applied to illustrate Tao and Teh.

Lakoff and Johnson (1980) define the highlighting and hiding effect of metaphor as follows: by virtue of metaphor mapping, only some characteristics of the target domain are highlighted at the expense of others when metaphorically conceptualizing a topic. The source domains separately focus on different aspects of the single concept, Tao or Teh. In other words, each source domain in the metaphor serves a purpose and allows us to understand one aspect of this concept in terms of a more clearly delineated concept.

Our discussion will proceed from two aspects: one is the coherence among five aspects of one abstract concept, Tao and Teh; the other is the coherence between two or more conceptual metaphors having the same target domain but not the same source domain.

A. Tao Is Water Nourishing Life

The conceptual metaphor, TAO IS MOTHER NOURISHING LIFE, is use to discuss the ontological being of Taoism. Tao can be felt everywhere and it is the origin of all substances.

The word Nothingness may be used to designate the beginning of Heaven and Earth; the word Existence may be used to designate the mother of all things. (Chapter 1)

(11) The great Tao is felt everywhere, extending in all directions. All things grow on it but it never declines them. It accomplishes its great task without claiming to merit. It breeds all things without claiming to be their master; it can be called small. All things finally return to it; and it never claims to be their master; and it can be called great. It becomes great because it never claims to be great. (Chapter 34)

(12) Tao begets the One; the One consists of Two in opposition (the Yin and Yang); the Two begets the Three; the Three begets all things of the world. (Chapter 42) 
(13) Tao begets all creature; virtue rears them; substance gives them shape; forces in opposition accomplish them. (Chapter 51)

The cohesive chain can be easily found, including words or expressions like, nothingness, being have, at the very beginning, mother, food, produce, etc. Tao is profound like the originator of all things, and exists everywhere, in (10), (11). Tao is the origin of all things and the universe is compared to Water nourishes life, mother bears a baby, for example in (12) and (13). Water is vital to life and we can not live without it, so does TAO. Water is, in nature, flexible, subtle, cold, warm, tender, powerful, etc. The same can be said of TAO, which exists everywhere, being various in form. In this ontological metaphor, the target domain Tao is abstract, unfamiliar while water is familiar and concrete to ordinary people. Lao Tzu assumes Tao is of vital importance to a man in his social life, which are compared with water to all living creatures and mother to a baby.

(14) I am indeed different from them all, because I take the greatest interest in obtaining Tao. (Chapter 20)

(15) There is a thing integratedly formed and born earlier that Heaven and Earth. Silent and empty, it relies on nothing, moving around for ever. We may regard it as the mother of all things. I do not know its name, so I call it as Tao.(Chapter 25)

(16) The universe has a beginning Tao; the beginning functions as the mother of all things. If you know the mother, you get to know her children (all things). You keep the mother, you will be a sage all your life. (Chapter 52)

(17) When there is the principle of governing the state, the government can long endure. This is called the Tao of deep roots and sturdy stems by which one can enjoy a long life. (Chapter 59)

TAO IS MOTHER can be seen in (17). Mother is adopted as an indication of Tao origins and nourishes all creatures in the world. Tao should be loved and respected as our mother and we behave ourselves as our mother tells us. On the other hand, mother is female, owning all properties of a female, being subtle, gentle, kind, etc., which entails another principle, preferring to be the weak. We will have a deeper discussion on it in the next section.

(18) Tao never dies; it is a deep womb, called the root of Heaven and Earth. (Chapter6)

(19) Tao never dies; it is a deep womb.(Chapter 6)

(20) Tao is to the world what the river and the sea are to the countless streamlets. (Chapter32)

(21) All the streamlets flow towards the river and the sea, because the latter takes the lower position, hence the latter becomes the king of countless valleys. (Chapter 60)

(22) A large state should play the role of female, just like the lowest reaches of a river. Where all the other streams meet. The female always conquers the male by gentleness, because the gentle female always takes the lower position. (Chapter 61)

(23) Simple and natural like the uncarved block; vacant and deep like a valley. (Chapter 15)

(24)Though knowing what is masculine, you are ready to play the role of female and content to be a stream in the world, you will be accompanied by the eternal virtue, and return to be a baby. (Chapter 28)

(25) The great virtue resembles the valley. (Chapter 41)

To illustrate his ideas more accurately, Lao Tzu creates another metaphor, TAO IS VALLEY listed in the above examples. The valley represents the hollow, the womb and mother of all things, the Yin or female. We can say that TAO IS MOTHER and TEH IS MOTHER are closely connected with TAO IS VALLEY and TEH IS VALLEY. It occurs that mother and valley have overlappings in this metaphor. They harbor all and take in above examples from(14)whatever imposed upon them. The same source domain, mother, in Tao, nurturing the child is highlighted; in Teh, mother as female, being the weak is highlighted.

It involves one target domain, Tao and three different source domains, water, mother, valley and they form a set of parallel classification. In contrast to super-subordinate relation which involves different levels of classification including super-ordinate and subordinate level, parallel categorization refers to a set of items which are at the same level within one "family". In other words, they are parallel since they are at the same level of categorization. There is no general-specific or specific-general relationship here.

\section{B. Tao Is Water Flowing Downwards}

The conceptual metaphor, TAO IS WATER FLOWING DOWNWARDS, is adopted to illustrate that Taoism is a practical guide to worldly affairs. Tao and Teh emphasize the importance of taking the lower position and prefer being the weak to the strong.

(26) Nothing in the world is more supple than water; yet nothing is more powerful than water in attacking the hard and strong. Why? Because nothing can take its place. Every one in the world knows that the supple is more rigid than the hard, yet no one so far can put the knowledge into practice.(Chapter 78)

(27) A large state should play the role of female, just like the lowest reaches of a river, where all the other steams meet. The female always conquers the male by motionless, because the motionless female always takes the lower position.(Chapter 61)

(28) Names are once given, limitations are thereby known. The knowledge of limitations helps avoid danger. Tao is to the world, what the river and the sea are to the countless streamlets.(Chapter 32)

(29) All the streamlets flow towards the river and the sea, because the latter takes the lower position.(Chapter 66)

Water fluids and shapes itself by its container and routes. The same holds true for Tao and Teh. Lao Tzu suggests individuals or rulers learn from water and adjust to situations whatever they are. We are similar in that water always 
goes to the lower place just as man should be humble and not always hold his head up. Lao Tzu draws the conclusion that people should behave on anti-competition and inaction. He thinks that water can serves as a best expression to this principle and the word, water appears on numerous occasions in this book. In (26), water approaches all things instead of contending with them. It prefers to dwell where no one would like to stay; hence it comes close to Tao.

(30) Bow down and you are preserved; bend and you can be straight; hollow, then new; worn, then full; seek a little and you get a lot; thus the sage adheres to this

Tao and regards it as the pattern of all things. Show off yourself not and you become conspicuous; regard yourself not as infallible and you become illustrious; and you become illustrious; brag about yourself not and you gain achievement; boast of yourself not and you become a head. One does not contend with others, so nobody in the world can win him in contention. The ancients' saying "Bow down and you are preserved" is surely not an empty saying, which can be really proved effective. (Chapter 22)

Keeping being weak is subtly profound. In examples from (26) to (30), though knowing what is masculine, you are advised to play the role of female. It generates another conceptual TAO IS FEMALE.

THE WEAK OUTWEIGHS THE STRONG. is one important embodiment in Laoism. The weak conquers the strong, in (26) and (27). Hence a realistic man should always take the side of the weak.

In (26), the perfect goodness is like water; water approaches all things instead of contending with them. Many followers are advised to be committed to the Tao and Teh, for it helps its seekers over difficulties and clear up their confusion, keeping carefree. Possibly having painfully witnessed a world of injustices and troubles caused by hostilities among mankind, Lao Tzu advocates the advantages of anti-competition.

(31) Hence the large can annex the small one; the small state can gain the trust of the large one by taking the lower position, the case being either the former or vice versa. The large state wants to put the small one under its protection, the small state wants to be shielded by the large one, thus both can satisfy their own wishes. (Chapter 61)

(32) That is why the humble is the root of the noble, and the high is based on the low. (Chapter 39)

By analogy, the thought is further developed so that it becomes applicable in many aspects of life. Lao Tzu knows well a clever man should know how to willingly stay on the degraded position though he is actually powerful. Though knowing what is masculine, you are ready to play the role of female and content to be the lowest reaches of the world.

(33) You are ready to play the role of the disgraced and content to be a valley in the world. (Chapter 28)

(34) Though knowing what is masculine; you are ready to play the role of female and content to be a stream in the world. (Chapter 28)

Based on this overlapping entailment, the two conceptual metaphors make the coherence between them, and then the whole text is coherent based on the coherence between the two conceptual metaphors. Though different target domain, sharing the same properties as overlapping entailment.

\section{Tao Is Water That Is Pure}

The conceptual metaphor, TAO IS WATER THAT IS PURE, serves as a way to demonstrate the methodology of Taoism. In Tao and Teh, water is pure is compared to goodness is genuine and true.

(35) The perfect goodness is like water; water approaches all things instead of contending with them. It prefers to dwell where no one would like to stay; hence it comes close to Tao. A man of perfect goodness chooses a low place to dwell as water; he has a heart as deep as water; he offers friendship as tender as water; he speaks as sincerely as water; he rules a state as orderly as water; he does a thing as properly as water; he takes action as timely as water. Like water, he never contends with others, so he never commits a mistake. (Chapter 8)

In (35), water and goodness shares another entailment that they are both pure. People are expected to practice kindness and compassion in a society under the guidance of Taoism. They should long for sincere friendship and various relationship among people. Lao Tzu calls for people to return to the native and act as an innocent child. Thus, another parallel metaphor, TAO \& TEH IS BABY, is generated to describe the simplicity harbored in one's heart.

The following is a set of conceptual expressions drawn from the conceptual metaphor, TAO \& TEH IS BABY. From the BABY metaphor we can draw a group of words, like being soft, little babies, children.etc. serving as the cohesive faction. A baby is said to be innocent, carefree from worldly affairs and being the weak, which, on the other hand, testifies one preaching of Laoism that one should always be ready to take the lower position and be humble.

(36) Though concentrating on breathing exercises (Qigong) to be supple, can you finally become as supple as a baby? (Chapter 10)

(37) While I, alone and inactive, remain aloof and indifferent, like a baby that has not yet learned to smile. (Chapter 20)

(38)You will be accompanied by the eternal virtue, and return to being a baby. (Chapter 28)

(39) When the sage governs the world, he weakens his will and simplifies the people's minds. The people are all preoccupied with their eyes and ears, the sage helps them return to the childhood state. (Chapter 49)

(40) A man of prodigious virtue is just like a newly-born baby. Its bones and muscles are weak and supple, yet its hold is tight. It cries all day long, yet its throat does not become hoarse; this is because it is at the height of harmonious vim and vigor. To know harmony is to know the law of unity; to know the law of unity is to know discernment.(Chapter 55) 


\section{Tao Is Water That Is Static}

The conceptual metaphor, TAO IS WATER THAT IS STATIC, is a key to apprehend the dialectic law of Laoism. Deep water in the valley is still, static and unperturbed is, here, compared to people who has a peaceful mind and live a simple life, being content through oneself, as in (41).

(41) A man of perfect goodness chooses a low place to dwell as water; he has a heart as deep as water. (Chapter 8)

(42) I try my best to be in an extreme emptiness of mind; I try to keep myself in a state of stillness. From the vigorous growth of all things I perceive the way they move in endless cycles. All things, full of vitality, finally return to their own roots. Returning to roots means stillness also means a return to destiny. A return to destiny is known as the law of eternity. To understand the law is known as enlightening. He who is ignorant of the law, if acting rashly, will be in great trouble. But he who knows the law is tolerant, and the tolerance leads to impartiality, impartiality to thoroughness; thoroughness to nature; nature to Tao; Tao to eternity. Thus he will not be endangered all his life. (Chapter 16)

(43) Keep being simple in nature and mind, discard selfishness and weaken desires. Discard cultural knowledge and worries will disappear. (Chapter 19)

A peaceful and tranquil mind free from the world's turmoil is needed and that is one integrated part of Teh. Big rivers or lakes are so big that they cover anything thrown into them. It signifies that a person practicing Tao and Teh also takes in all forms of drawbacks, frustrations, obstructions.

(43) Those ancients who were well versed in Tao, were so subtle, mysterious and profound as to escape understanding. The description of them is surely perfunctory: turbid like muddy water, quiet and calm like the great sea; drifting as if they would never stop. Who can end the muddiness and make the muddy settle and gradually become clear? Who can be at rest and yet, stirring, slowly come to life? He who is in possession of this Tao will not seek completeness. Just because he will not seek completeness, he can be both old and new. (Chapter 15)

The reason is that dreggy water becomes clear if it is kept in quietness for a longer time. Quietness signifies one searching for self-examination and meditation for living in a society which obscures our nature. From it, Lao Tzu exemplifies the meditation method of pursuing Teh. Lao Tzu taught people that they keep peace in their troubled hearts and minds, free from doubt and uncertainty. Man's soul should long for quietness in order to practice the moral rules and regulations in (43). On the other hand, Tao is like water that is dynamic and reflects all things like a mirror. It nourishes all in this world and contains unimaginable power.

(44) Keep the people from contention by disregarding men of abilities; keep the people from theft by not valuing rare goods; keep the people from the disturbed state of mind by concealing what is desirable. (Chapter 3)

(45) One does not contend with others, so nobody in the world can win him in contention. (Chapter 22)

He strongly advocated anti-competition, as in (44) and (45). The principle of anticompetition above, if put into practice by all people, will surely give rise to a world of peace. The inaction theory with a painstaking effort will end ignorance and contradictions. Therefore, Tao is an indication of complete understanding of the traditional Chinese spirit, returning to a harmonious society.

(46) Knowing contentment avoids disgrace; knowing when to stop avoids danger. Thus one can be long in safety. (Chapter 44)

(47) Thus the contentment of feeling content is an eternal contentment. (Chapter 46)

It indicates that Lao Tzu advocates people to live a simple and natural life in (46) and (47). Vain efforts should be avoided and our inner world can be an untroubled one. Tranquility of mind should be kept in order to achieve inner peace, to shake off the world's dusty strife. He who is contented with himself will avoid disgrace, danger, and thus can be happy. In water, man swims like a fish completely free from interference of worldly chores. People live under Teh just like fish in the sea. This notion is enormously influential throughout history for thousands of years in China.

Thus the sage says, if I prefer inaction, the people will naturally crave for peace; if I act little, the people will be naturally rectified; if I am not meddlesome, the people will naturally become rich; if I get rid of desires, the people will naturally become simple. (Chapter 57)

(49) Though getting rid of your distracting thoughts for a deeper meditation, can you be devoid of blemish? (Chapter 10)

(50) He who seeks learning must increase his knowledge every day; he who seeks Tao must reduce his knowledge every day; he reduces and reduces until he reaches the state of inaction. (Chapter 48)

Man is said to be far from ignorance and obsession as long as he keeps seclusion. Lao Tzu teaches that deep meditation helps man a lot in perceiving the truth of the world, Tao. A successful meditation needs to get rid of one's distracting thoughts. Distracting thoughts stem from knowledge and desires. Knowledge is a chaotic system of concepts and ideas which are indubitably biased. Knowledge helps a lot just as it misleads us on many occasions. Culture itself functions as colorful glasses distorting our view of the physical world. Desires excite our bodies, befuddle our mind, distort our senses and reason, rendering us unable to observe and examine the world calmly and objectively. A deep meditation, therefore, summons up the great necessity of discarding knowledge and desires (49), (50) Though getting rid of your distracting thoughts for a deeper meditation, Can you be devoid of blemish? With body and mind being in perfect harmony and all distracting thoughts removed. Thus we enter into a state that our hearts are like "still water and flawless mirror." Happiness, in Taoism, should be gained by resorting to reason and illumination while reducing 
external stimulations to minimum. One should discard selfishness and weaken desires. The aim of moderation of desire is to be simple in nature and mind, and build up a society in which hypocrisy, trickery, suppression and exploitation are wiped out. Lao Tzu expresses it precisely and concisely by adopting the WATER metaphor and the BABY metaphor. The following (51) is the preachings provided by Lao Tzu.

(51) I have three most valuable things, which I hold and treasure: The first is mercy; the second is thrift; the third is unwillingness to take the lead in the world. (Chapter 67)

From the Water metaphor, Lao Tzu developed two metaphors TEH IS ROOT and TEH IS LORD in (52); (53) as illustrated in the following figure. (54) is another example showing that different conceptual metaphorical expressions also have a close relationship with each other. They are coherent at the deep discourse level.

(52) All things, full of vitality, finally return to their own roots. Returning to roots means stillness, also means a return destiny. A return to destiny is known as the law of eternity. To understanding the law is known as enlightening.(Chapter 16)

(53) Lightness leads to the loss of the root; restlessness leads to the loss of the lord. (Chapter 26)

(54) When there is the principle of governing the state, the government can long endure. This is called the Tao of deep roots and sturdy stems by which one can enjoy a long life. (Chapter 59)

The WATER metaphor, the MOTHER metaphor, the ROOT metaphor and the LORD metaphor have a close relationship with each other. The principles of Tao \& Teh, being vital, soft, powerful are found to be compared with mother, root, and lord of a country. These properties are highlighted in each source domain, though there are several different domains. Through these metaphors, the significance of Tao and Teh to people, is illustrated like, root to a tree; a mother to a baby and a leader to a country.

\section{E. Tao Is Water That Recycles}

Lao Tzu advocates that his Taoism exits everywhere and persists forever. Tao, in his terms, is born earlier than Heaven and Earth. Water flows its routes and its form varies, from vapor to ice, and from rain falling to the river bed again. Being changeable is, in essence, being eternal. Things always keep changing and unifying themselves.

(55) There is a thing integratedly formed and born earlier than Heaven and Earth. Silent and empty, it relies on nothing, moving around for ever. We may regard it as the mother of all things. I do not know its name, so I name it as Tao, and further name it as Great. Great is moving forward without stopping, extending to the remotest distance, and then returning to where it was. (Chapter 25)

(56) Man takes Earth as his model; Earth takes Heaven as its model; Heaven takes Tao as its model; Tao takes what is natural as its model. (Chapter 25)

According to Lao Tzu, there are various laws underlying all in the universe including Heaven, Earth, and Man. However, the best and the most functional laws are those which are most natural, or, in other words, are those which completely follow the Tao, way of nature, as in (56). Obviously, we have followed Taoism in a circle starting from the law of man, through the law of Heaven, of Earth, of Tao, to the laws of nature. Recycling is the movement of water, so is Tao. Tao inspires people to return to the nature and to lead a simple life.

As to Teh, the nature of man undergoes many changes. A man of great wisdom should not refrain from movement, just staying still to achieve tranquility of mind and deepen his perception. Only by practicing meditation can he live a secluded, simple and thrifty life. In modern society, the great expansion of modern science accompanies the intensified conflicts and contradictions among people and countries which urges a bridge built to reach a harmonious society. Return to nature, one of the key concepts in Taoism, once again echoes in modern people's heart. We can say that retrogression means both a retreat and progress, retreat from the age of hypocrisy to the age of simplicity. Simplicity is considered as a regression by some scholars, but the regression is deemed good for mankind, because the retrogression means a return to a society of peace and well being. Tao and Teh is complex on one hand, and on the other, simple at it uttermost. By WATER RECYCLES, Lao Tzu proposes that Tao and Teh are ontological, essential, eternal and should be a practical guide to dialectics, outlooks and so on. The following is the global coherence of metaphors analysed in The Book of Tao and Teh.

W: TAO \& TEH IS WATER

W1: TAO IS WATER NOURISHING LIFE

W2: TAO IS WATER FLOWING DOWNWARDS

W3: TAO IS WATER THAT IS PURE

W4: TAO IS WATER THAT IS STATIC

W5: TAO IS WATER THAT RECYCLES

Wi: TAO IS MOTHER; TAO IS VALLEY

Wii: TAO \& TEH IS FEMALE

Wiii: TEH IS BABY

Wiv: TEH IS ROOT; TEH IS LORD

S: TAO \& TEH RECYCLES 
$\mathrm{S}$

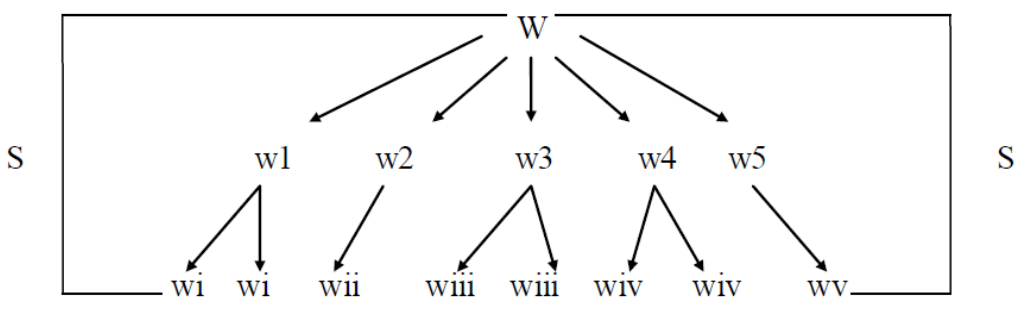

Figure 3. The Global Coherence of Metaphors in The Book of Tao and The

\section{Discussion}

Through the analysis of the metaphors in this pioneering book, we reach the conclusion that conceptual metaphor can account for the cohesion of the discourse and metaphorical expressions, especially lexis, are cohesive tokens to achieve explicit coherence in texts. And we confirm the hypothesis that conceptual metaphor in discourse can help to guarantee textual cohesion and coherence. The systematicity and coherence of metaphor is of great importance to discourse construction. There are four important ways to achieve coherence.

Firstly, it is through the overlapping entailments between the target domain and the source domain, because the source domain provides the common ground for coherence.

Secondly, there are also overlapping entailments between a set of different source domains. Or source domains have a very close relationship with each other. In this discourse, Tao and Teh shares many entailments as discussed above.

Thirdly, the source domain separately focuses on different aspects of one concept. In other words, each source domain in the metaphor serves one purpose and illustrates one aspect of the concept in terms of a clearly delineated concept. The description of different source domains which serve different purposes are coherent in the sense that the different purposes are unified for one concept and they are just various perspectives of a single object.

Finally, the systematicity of metaphor contributes a lot to global coherence. Metaphorical concepts are systematic in their own right and thus the metaphorical expressions form a coherent system and then the text with those metaphorical expressions is coherent.

We analyze metaphors in Taoism for it is fundamental to the understanding of traditional Chinese culture and civilization. Lao Tzu applies Tao to the explanation of history, society and life, offering a system of views which later on, to a considerable degree, function as models which classical Chinese politics, economy and culture are fashioned. TAO IS WATER ensures continuity of the whole passage with its entailments closely connected. Its systematicity serves as the basis or foundation of the whole system construction.

\section{REFERENCES}

[1] Black, M. (1993). More about Metaphor: Metaphor and Thought. Ed. Ortony, A. Cambridge: Cambridge University Press.

[2] Cameron L. \& Low, Q. (2001). Researching and Applying Metaphor. Shanghai: Shanghai Foreign Language education Press.

[3] Cameron, J. (2002). Metaphor in Educational Discourse. London \& New York: Continuum Press.

[4] Diane, P. (2000). The Cohesive Role of Cognitive Metaphor in Discourse and Conversation. Berlin: Mouton De Gruyter.

[5] Gibbs, R. W. and G. J. Stern (1999). Metaphor in Cognitive Linguistics. Amsterdam: John Benjamins Publishing Company.

[6] Goatly, A. (2000). Critical Reading and Writing. London and New York: Routledge.

[7] Halliday, M. A. K. (2000). An Introduction to Functional Grammar. Beijing: Foreign Language Teaching and Research Press.

[8] Hoey, M. (1991) Patterns of Lexis in Text. Oxford: Oxford University Press.

[9] Kovecses, Zoltan. (2002). Metaphor: A Practical Introduction. New York: Oxford University Press.

[10] Lakoff, G. \& M. Johnson. (1980). Metaphors We Live By. Chicago: The University of Chicago Press.

[11] Lakoff, G. (1987). Women, Fire and Dangerous Things. Chicago: The University of Chicago Press.

[12] Lakoff, G. (1993). The Contemporary Theory of Metaphor: Metaphor and Thought. Cambridge: Cambridge University.

[13] Langacker, R. W. (2004). Foundations of Cognitive Grammar. Beijing: Beijing University Press.

[14] Ponterotto, D. (2003). The cohesive role of cognitive metaphor in discourse and conversation. Berlin and New York: Mouton de Gruyer.

[15] Ricoeur, P. (1986). The Rule of Metaphor. London: Routledge and Kegan Paul.

[16] Santa Ana, O. Brown. (2002) Tide Rising: Metaphors of Latins in Contemporary American Public Discourse. Austin, TX: University of Texas Press.

[17] Steen,G. (1994). Understanding Metaphor in Literature: An Empirical Approach. New York: Longman.

[18] Stern, J. (2000). Metaphor in Context. Cambridge, Mass: MTT Press.

[19] Taylor, J. R. (2002). Cognitive Grammar. Oxford: Oxford University Press.

[20] van Dijk, T. A. (1997). Discourse as Structure and Process. London: SAGE Publications.

[21] Ungerer, F. \& Schimid, H. J. (2001). An Introduction to Cognitive Linguistics. Beijing: Foreign Language Teaching and Research Press.

[22] Zhengkun Gu. (2007). Tao and Teh. Beijing: China publications Co.Ltd. 
Xiaojing Yin, a College English teacher for English major students in Shandong University of Finance and Economics in Jinan, has been teaching college English for ten years. During this decade, she published several papers and translated two piece works of American literature. Her research field is linguistics. 